\title{
The Effect of Internal Trust on the Participation Willingness of Farmers' Professional Cooperatives Members
}

\author{
Xiaofan Chen, Chengchao Sun \\ School of Humanities and Law, Zhejiang Agriculture and Forestry University, Hangzhou, China \\ Email: chenxiaofan0425@163.com
}

How to cite this paper: Chen, X.F. and Sun, C.C. (2019) The Effect of Internal Trust on the Participation Willingness of Farmers' Professional Cooperatives Members. Open Journal of Social Sciences, 7, 325-333.

https://doi.org/10.4236/jss.2019.78023

Received: August 2, 2019

Accepted: August 23, 2019

Published: August 26, 2019

Copyright $\odot 2019$ by author(s) and Scientific Research Publishing Inc. This work is licensed under the Creative Commons Attribution International License (CC BY 4.0).

http://creativecommons.org/licenses/by/4.0/

\begin{abstract}
In order to study the factors influencing the trust and participation willingness of Farmers' professional cooperatives, this paper conducts a field survey of seven Farmers' professional cooperatives in Linan District of Hangzhou City, using factor analysis and regression analysis to analyze the members of cooperatives. The results show that the personality, organization, prospect and trust factors within the Farmers' professional cooperatives have significant effects on the willingness to participate. Among them, the organizational factors have the greatest impact on the willingness to participate, while the relationship factors have no significant impact on the willingness to participate.
\end{abstract}

\section{Keywords}

Cooperatives, Interpersonal Trust, Organizational Trust, Willingness to Participate

\section{Introduction}

Over the past decade, Document No. 1 of the Central Committee of China has issued several policies to support Farmers' professional cooperatives. With the continuous improvement of the external environment, the number of cooperatives has made rapid progress. By the end of February 2018, 2.044 million Farmers' professional cooperatives had been registered in accordance with the law, and 117.59 million farmers had joined the cooperatives, accounting for $48.1 \%$ of the total number of farmers in the country. In the rapid growth of cooperatives, there are such problems as "shell society", "high quantity, low quality" and "loose organization" which restrict the development of modern agriculture. 
There are many reasons for these problems, among which some scholars attribute the reasons to the lack of endogenous motivation, loose management, excessive dependence on the government and rural elites, which affect the sustainable development of Farmers' professional cooperatives. Some scholars believe that this is closely related to the degree of Farmers' trust in cooperatives in rural society. Whether farmers can actively participate in the establishment, operation and development of cooperative organizations and really move towards cooperation depends on their trust in cooperatives. Trust can reduce the transaction cost within the cooperation and improve the efficiency of the organization. It is also the premise of cooperation. If cooperatives want to develop continuously, they must overcome many problems and win Farmers' trust in cooperative organizations. From the perspective of trust, this paper studies the relationship between trust and members' willingness to participate. Members' willingness to participate is an evolving process. According to the factors of subject cognition and external environment, members will constantly adjust and change, which will affect their enthusiasm to participate in affairs. Members are the main body and backbone of cooperatives. Only by fully mobilizing their enthusiasm for participation can we put the system, policy and development into practice. Therefore, factor analysis and regression analysis are used to analyze the factors affecting the willingness of members to participate in order to have a more comprehensive understanding of cooperative members' participation behavior.

\section{Literature Review}

In the existing studies, many scholars have studied the trust of cooperatives from different perspectives, and have achieved a series of valuable research results. Luhmann (1979), a foreign scholar, thinks from the perspective of trust type, divides trust into interpersonal trust and institutional trust, and believes that interpersonal trust is based on feelings and has the characteristics of alienation and proximity, which also results in the strength of trust, which is different from the "difference order pattern" proposed by Mr. Fei Xiaotong [1]. Mc Allister (1995) divides trust into emotional trust and cognitive trust from the perspective of trustees. He believes that emotional trust is based on the care and care of trustees and the emotional relationship between trustees. Cognitive trust is the trustees' rational judgment of trustees' credibility based on their previous experience of communication [2]. Dirks and Ferrin (2002) argue that there are two different theoretical perspectives on leadership trust theory, namely, characteristics. View and Relation View. Cognitive trust is related to feature view, while emotional trust is similar to relationship view [3]. Mayer et al. (1995) provided a more inclusive and operable classification of trust, which divided quality trust into the following three categories: competence based trust, benevolence based trust and integrity based trust [4]. Xu Xujun (2011) divides trust into interpersonal trust and systematic trust from the perspective of trust within cooperatives, and then constructs a framework of influencing factors of trust within cooperatives from 
three dimensions: trusted party, trusted party, trusted party and trusted party [5]. Liu Yuxiang (2012) further pointed out that the relationship and system are two ways to produce the trust of cooperative members, and considered that the willingness of members, the needs of members, individual characteristics and family characteristics are four factors that affect the trust of cooperative members, but the role of the former two factors is not as obvious as that of the latter two factors [6]. Yang Liu and Gao Jianzhong. (2013) believed that the relationship between cooperatives and their members had the greatest impact on the trust of cooperative organizations, and the closeness of the relationship between the president and the members was the most important factor affecting the trust of the members to the president [7]. Wanjianghong and Geng Yufang (2015) mainly studied the willingness and behavior of participation of members from interpersonal trust and systematic trust. The results show that systematic trust has a significant impact on Farmers' willingness and behavior to participate [8]. Based on the "risk-trust" theory, the analysis of Yang Xuemei and Wang Zhengjun (2018) shows that the trust of members has a significant positive impact on the participation behavior of members. The higher the trust of members, the higher the participation degree of members, and then can improve the participation degree of members [9]. Guo Hongdong, Yang Haizhou and Zhang Ruojian (2008) studied members' trust in the president based on data from Zhejiang Province. He believed that the president's ability, personality, relationship between the president and the members and the president's concern for the members would affect the trust of the members to the president [10]. From the perspective of the trusted, Huang Juan (2009) believed that the trust degree of members to the cooperative leader mainly depends on the ability of the leader, followed by the motivation of the leader, the reputation of the leader and the image of the leader [11]. There are different understandings of the concept of trust in different fields, but there is a consensus that trust is the basis for dealing or exchanging relationship Trust is a stable concept, which maintains the shared value and stability of the society. It is the tendency of individual attitude towards others. Trust is an important social capital, a prerequisite for the existence of cooperative economic behavior, and also a kind of interest expectation's. The existing literature mainly focuses on the influencing factors of trust and its impact on the development of cooperatives, but there is little in-depth study of the willingness of members of cooperatives to participate from the perspective of trust. According to the literature, we find that some scholars divide trust into interpersonal trust, institutional trust, organizational trust, willingness trust, ability trust and so on. Combining with the existing research, this paper divides trust into interpersonal trust and organizational trust. From these two levels, we analyze the impact of trust on the willingness of members to participate in cooperatives. Participation intention is a kind of behavior intention. People can predict the actual behavior in the future through behavior control. Only when cooperatives have endogenous motive force, can their overall development and operation truly enter the formal stage. Therefore, based on the perspective of 
trust, this paper measures the key factors affecting members' willingness to participate through factor analysis, and provides some ideas for the sustainable development of cooperatives.

\section{Research Design}

\subsection{Data Sources and Sample Characteristics}

In order to explore the relationship between trust and willingness to participate in cooperatives, the author first visits cooperatives and has a more comprehensive understanding of them, then carries out pre-survey, and gradually revises and improves the questionnaire. The data used in this paper are from the author's questionnaire survey on members of Farmers' professional cooperatives in Linan District, Hangzhou City, Zhejiang Province, from July to August 2018. According to the normal operation of cooperatives, relative norms and other factors, seven farmer professional cooperatives mainly planting species were selected to conduct field research, and their members were surveyed by questionnaire. The questionnaires involved the information of gender, age, education level, interpersonal trust and organizational trust of cooperative members, as well as their willingness to participate. A total of 135 questionnaires were distributed, 130 of which were valid, with an effective rate of $96.2 \%$. The respondents are listed in Table 1.

From Table 1, we can see that in terms of gender, most of the members interviewed were male; $56.2 \%$ were male and $43.8 \%$ were female. As for age structure, the members interviewed mainly concentrated in the age group of over 60 years old, followed by 50 - 60 years old, indicating that most of the members of cooperatives are middle-aged and old-aged people at present. 57\% of the respondents were junior high school or below, stating that most of the respondents had low educational level.

Table 1. Basic information of sample members.

\begin{tabular}{cccc}
\hline Characteristic & Classification Indicators & Frequency & Effective Proportion (\%) \\
\hline \multirow{2}{*}{ Gender } & Male & 73 & 56.2 \\
& female & 57 & 43.8 \\
Under 30 & 4 & 3.1 \\
Age & 30 - 40 years old & 4 & 3.1 \\
& 40 - 50 years old & 17 & 13.1 \\
& 50 - 60 years old & 45 & 34.6 \\
& Over 60 years of age & 60 & 46.2 \\
& Primary school and below & 27 & 20.8 \\
& Junior middle school & 47 & 36.2 \\
Degree of Education & high school & 35 & 26.9 \\
& Specialty & 17 & 13.1 \\
& Bachelor degree or above & 4 & 3.1 \\
\hline
\end{tabular}




\subsection{Interpretation of Variables}

Independent variable. This paper establishes two secondary indicators, interpersonal trust and organizational trust, under the first-level indicators of cooperative trust. Eight three-level indicators are set up under the second-level indicators of interpersonal trust, and six three-level indicators are set under the second-level indicators of organizational trust (Table 2). Liker's five-point score was used to measure trust. The variables were assigned in the order of "very disagreement (very distrust)", "very disagreement (not trust)", "general agreement (general trust)", "comparative agreement (comparative trust)" and "very consent (very trust)" in the order of $1-5$, respectively.

\section{Empirical Analysis}

\subsection{Factor Analysis}

Because there are many variables of trust in cooperatives, factor analysis method is used to reduce the dimensions of the indicators of interpersonal trust and organizational trust, thus a small number of representative, generalized and independent common factors are obtained. Before factor analysis, KMO test and Bartlett sphericity test were performed on the variables of interpersonal trust and organizational trust involving cooperatives using SPSS software. The results showed that the KMO value was 0.568 , the approximate chi-square value of Bartlett sphericity test was 766.478 , and the significant level was $0.0000<0.05$, which indicated that the data validity of the above 14 variables was high and suitable for factor analysis. Details are shown in Table 3.

Table 2. Variable description and statistical characteristics.

\begin{tabular}{cccc}
\hline \multirow{2}{*}{ Variable } & Definition & $\begin{array}{c}\text { Mean } \\
\text { Standard }\end{array}$ & Deviation \\
\hline A1 & The president's management ability is very strong & 3.85 & 1.149 \\
A2 & The president has a high prestige in the local area & 3.95 & 0.686 \\
A3 & Presidents can act in accordance with words & 3.71 & 0.849 \\
A4 & President can act impartially & 3.91 & 0.752 \\
A5 & The president's network is strong. & 3.45 & 0.997 \\
A6 & The president will not harm the & 4.01 & 0.676 \\
A7 & collective interest for personal benefit & 4.00 & 0.715 \\
A8 & The president has a good relationship with his members & 3.78 & 0.915 \\
B1 & Cooperatives are reliable & 3.48 & 0.780 \\
B2 & Cooperatives can help members & 4.12 & 0.659 \\
B3 & Cooperatives safeguard the interests of their members & 3.82 & 0.713 \\
B4 & Cooperatives have good prospects for development & 3.05 & 1.088 \\
B5 & Open and transparent decision-making & 3.55 & 0.881 \\
B6 & management of cooperatives & 3.55 & 1.149 \\
\hline & The degree of trust in existing cooperatives & & \\
\hline
\end{tabular}


Table 3. Factor load matrix after rotation.

\begin{tabular}{|c|c|c|c|c|c|}
\hline \multirow{2}{*}{ project } & \multicolumn{5}{|c|}{ Ingredients } \\
\hline & 1 & 2 & 3 & 4 & 5 \\
\hline The president's management ability is very strong. & 0.102 & 0.106 & 0.262 & -0.814 & 0.262 \\
\hline The president has a high prestige in the local area. & 0.204 & -0.177 & 0.794 & -0.029 & -0.203 \\
\hline The president can be consistent in his words and deeds. & 0.664 & -0.054 & 0.287 & 0.546 & 0.014 \\
\hline The president can act impartially & 0.419 & -0.678 & 0.300 & 0.024 & 0.072 \\
\hline The president's network is strong. & -0.157 & 0.205 & 0.846 & 0.037 & 0.175 \\
\hline The president will not harm the collective interest for personal benefit & 0.003 & 0.399 & 0.443 & -0.112 & 0.488 \\
\hline The president has a good relationship with his members. & -0.238 & 0.793 & 0.127 & 0.146 & 0.080 \\
\hline Trust in current elders & 0.765 & -0.071 & 0.216 & -0.216 & 0.305 \\
\hline Cooperatives are reliable & 0.122 & 0.106 & -0.121 & 0.017 & 0.752 \\
\hline Cooperatives can help members & -0.661 & 0.259 & 0.135 & 0.261 & -0.075 \\
\hline Cooperatives safeguard the interests of their members & -0.729 & -0.036 & 0.127 & -0.056 & 0.525 \\
\hline Cooperatives have good prospects for development & -0.115 & 0.225 & 0.066 & 0.703 & 0.187 \\
\hline Open and transparent decision-making management of cooperatives & 0.139 & 0.851 & -0.002 & 0.027 & 0.203 \\
\hline The degree of trust in existing cooperatives & -0.161 & 0.372 & -0.548 & 0.331 & 0.396 \\
\hline Nomenclature of new factors & $\begin{array}{l}\text { Personality } \\
\text { factor }\end{array}$ & $\begin{array}{l}\text { Organization } \\
\text { factor }\end{array}$ & $\begin{array}{l}\text { Relationship } \\
\text { factor }\end{array}$ & $\begin{array}{l}\text { Prospect } \\
\text { factor }\end{array}$ & $\begin{array}{l}\text { Trust } \\
\text { factor }\end{array}$ \\
\hline Characteristic value & 3.409 & 2.406 & 1.754 & 1.613 & 1.015 \\
\hline KMO value & \multicolumn{5}{|c|}{0.568} \\
\hline Bartlett's sphericity test & \multicolumn{5}{|c|}{$x^{2}=766.478 \mathrm{df}=91 \mathrm{Sig}=0.000$} \\
\hline Contribution rate of variance (\%) & 16.981 & 16.675 & 15.714 & 12.294 & 11.169 \\
\hline Cumulative contribution rate of variance (\%) & 16.981 & 33.657 & 49.371 & 61.665 & 72.834 \\
\hline
\end{tabular}

\subsection{Regression Analysis}

In order to obtain a good factor structure, the principal component analysis method is used to extract common factors. Five initial factors are selected according to the principle that the eigenvalue is greater than 1 . In order to better explain and name the factors, this study uses the maximum variance method to rotate the matrix and make the coefficients differentiate into two levels: 0 and 1. The rotating factor load matrix is shown in Table 3. In this paper, the independent variables with larger factor load coefficient are classified and five common factors are extracted. They are named as "personality factor", "organization factor", "relationship factor", "prospect factor" and "trust factor". The cumulative variance contribution rate of the five common factors is $72.834 \%$. The results show that the five common factors can largely replace the original 14 observation variables to explain the factors affecting the trust of cooperatives. Among the characteristics of personality factors, trust in the current president and consistency of words and deeds are two important factors; among the characteristics 
of organizational factors, transparency in decision-making and management of cooperatives is the decisive factor; among the characteristics of relationship factors, the strong relationship network of the president and the high prestige of the president in the local area are the important factors; among the former, the former is the former. The development prospect of cooperatives is the decisive factor in the characteristics of scenic factors, and the reliability of cooperatives is the decisive factor in the characteristics of trust factors.

On the basis of principal component analysis, 14 original observation variables affecting interpersonal trust and organizational trust of cooperatives are simplified to five common factor variables, and the information of 14 original observation variables is converted into five common factor factors. Then, five common factors are analyzed by linear regression to determine whether each factor is significant or not and the degree of influence. According to the regression model, the R-square of the model is 0.575 and the constant is 2.543 . Therefore, the regression model is established as $y=2.543-0.394 x_{1}+0.437 x_{2}+$ $0.379_{X_{4}}+0.359_{X_{5}}$. Details are shown in Table 4.

From Table 4, we can see that personality factor, organization factor, prospects factor and trust factor are significant at the 5\% statistical test level, and the standardized regression coefficient of organization factor is the largest, indicating that organization factor has the greatest relative effect on the willingness to participate in cooperatives among the five common factors. Secondly, we also find that the relationship factor has no significant impact on the willingness to participate in cooperatives.

\section{Conclusion}

Based on an empirical study of the internal members of seven Farmers' professional cooperatives in Linan District, the relationship between trust and willingness to participate in Farmers' professional cooperatives is analyzed. The results show that the personality, organizational, prospects and trust factors of cooperatives have a significant impact on the willingness of internal members to

Table 4. Model regression results of influencing factors of trust in cooperatives.

\begin{tabular}{|c|c|c|c|c|c|c|}
\hline \multirow{2}{*}{ Variable } & \multirow{2}{*}{ B } & \multirow{2}{*}{$\begin{array}{c}\text { Standardized } \\
\text { regression } \\
\text { coefficien }\end{array}$} & \multirow{2}{*}{$\begin{array}{c}\text { Standard } \\
\text { error }\end{array}$} & \multirow{2}{*}{ Significance } & \multicolumn{2}{|c|}{$95 \%$ confidence interval of $B$} \\
\hline & & & & & Lower Limit & Upper Limit \\
\hline $\begin{array}{l}\text { Personality } \\
\text { factor }\end{array}$ & -0.394 & -0.375 & 0.068 & $0.000^{*}$ & -0.529 & -0.259 \\
\hline Tissue factor & 0.437 & 0.417 & 0.074 & $0.000^{*}$ & 0.291 & 0.583 \\
\hline $\begin{array}{l}\text { Relational } \\
\text { factors }\end{array}$ & -0.96 & -0.092 & 0.064 & 0.133 & -0.222 & 0.030 \\
\hline $\begin{array}{l}\text { Prospect } \\
\text { factors }\end{array}$ & 0.379 & 0.361 & 0.084 & $0.000^{*}$ & 0.212 & 0.545 \\
\hline Trust factor & 0.359 & 0.342 & 0.073 & $0.000^{*}$ & 0.214 & 0.504 \\
\hline
\end{tabular}


participate, while the relationship factors are related to the willingness to participate in Farmers' professional cooperatives. Members' trust plays an important role in the willingness to further participate in cooperatives. It can promote members' participation in cooperatives, mobilize their enthusiasm and improve their participation. Therefore, it is necessary to establish a good trust environment. Firstly, talent is the endogenous driving force for the development of cooperatives. Through professional training, technical guidance and experience exchange, the skills of the president and managers of cooperatives should be improved. The president and managers should pay attention to both internal and external training, enhance the sense of responsibility, and be able to convince others. Secondly, the cooperatives should be managed in a standardized way, and internal decision-making should be made public: transparently cultivate the sense of ownership of members; furthermore, establish a good social network, make full use of social resources, for the benefit of cooperatives; finally, we should strengthen the members' understanding of the cooperative organization itself, increase the sense of recognition of cooperatives, and use lectures, propaganda and other means to let members truly understand cooperatives.

\section{Conflicts of Interest}

The authors declare no conflicts of interest regarding the publication of this paper.

\section{References}

[1] Luhmann, N. (1979) Trust and Power. John Wiley and Sons, New York.

[2] Hansen, M.H. and Morrow, L. (2002) The Impact of Trust on Membership Retention, Performance, and Satisfaction: An Exploratory Study. International Food and Agribusiness Management Review, 5, 41-59. https://doi.org/10.1016/S1096-7508(02)00069-1

[3] Dirks, K.T. and Ferrin, D.L. (2002) Trust in Leadership: Meta-Analytic Findings and Implications for Research and Practice. Journal of Applied Psychology, 87, 611-628. https://doi.org/10.1037//0021-9010.87.4.611

[4] Mayer, R., Davis, J. and Schoorman, F. (1995) An Integrative Model of Organizational Trust. Academy of Management Review, 20, 709-734. https://doi.org/10.5465/amr.1995.9508080335

[5] Xu, X.C. and Zhou, X.L. (2011) Research on the Influencing Factors of Trust in Farmers' Professional Cooperatives Based on the Perspective of Members. Market Modernization, No. 16, 104-105.

[6] Liu, Y.X. (2012) Analysis of the Influencing Factors of Trust in the Development of Farmer Specialized Cooperatives-Taking Shaanxi Province as an Example. Agricultural Economic Issues, No. 9, 64-69.

[7] Yang, L. and Gao, J.Z. (2013) Analysis of Influencing Factors of Members' Trust in Farmers' Professional Cooperative Organizations. Guizhou Agricultural Science, 41, 236-238.

[8] Wan, J.H. and Geng, Y.F. (2015) Research on Interpersonal Trust and Systematic Trust of Cooperatives. Agricultural Economic Issues, No. 7, 80-89. 
[9] Yang, X.M., Wang, Z.J. and Liu, J. (2018) Trust, Risk Perception and the Participation Behavior of Members of Cooperatives. $L i$, No. 4, 117-123.

[10] Guo, H.D., Yang, H.Z. and Zhang, R.J. (2008) Analysis of the Factors Affecting the Trust of Farmers' Professional Cooperatives Members in the Presidents: Based on the Survey of Some Members in Zhejiang Province. Rural Economy of China, No. 8, 52-61.

[11] Huang, J. (2009) Analysis on the Influencing Factors of Trust and Farmer's Cooperative Demand. Agricultural Economic Issues, No. 8, 45-50. 